\title{
Technical note: Algal Pigment Index 2 in the Atlantic off the southwest Iberian Peninsula: standard and regional algorithms
}

\author{
Priscila Goela $^{1,2}$, Sónia Cristina ${ }^{1,2}$, Tamito Kajiyama ${ }^{3}$, John Icely ${ }^{1,2}$, Gerald Moore ${ }^{4}$, Bruno Fragoso ${ }^{1,2}$, and \\ Alice Newton ${ }^{1,5}$ \\ ${ }^{1}$ Centre for Marine and Environmental Research, FCT, University of Algarve, Campus de Gambelas, 8005-139 Faro, Portugal \\ ${ }^{2}$ Sagremarisco Lda., Apartado 21, 8650-999 Vila do Bispo, Portugal \\ ${ }^{3}$ FCT, University of Algarve, Campus de Gambelas, 8005-139 Faro, Portugal \\ ${ }^{4}$ Bio-Optika, Crofters, Gunnislake, PL18 NQ, UK \\ ${ }^{5}$ Norwegian Institute for Air Research-IMPEC, Box 100, 2027 Kjeller, Norway \\ Correspondence to: Priscila Goela (priscila.goela@gmail.com)
}

Received: 3 June 2016 - Published in Ocean Sci. Discuss.: 5 July 2016

Revised: 14 October 2016 - Accepted: 27 November 2016 - Published: 22 December 2016

\begin{abstract}
In this study, Algal Pigment Index 2 (API2) is investigated in Sagres, an area located in the Atlantic off the southwestern Iberian Peninsula. Standard results provided by the MEdium Resolution Image Spectrometer (MERIS) ocean colour sensor were compared with alternative data products, determined through a regional inversion scheme, using both MERIS and in situ remote sensing reflectances $\left(R_{\mathrm{rs}}\right)$ as input data. The reference quantity for performance assessment is in situ total chlorophyll $a$ (TChl $a$ ) concentration estimated through a phytoplankton absorption coefficient (i.e. equivalent to API2). Additional comparison of data products has also been addressed for TChl $a$ concentration determined by high-performance liquid chromatography. The MERIS matchup analysis revealed a systematic underestimation of TChl $a$, which was confirmed with an independent comparison of product map analysis. The study demonstrates the importance of regional algorithms for the study area that could complement upcoming standard results of the current Sentinel-3/OLCI space mission.
\end{abstract}

\section{Introduction}

The MEdium Resolution Image Spectrometer (MERIS) space sensor, operated by the European Space Agency (ESA) on-board the ENVISAT platform from 2002 to 2012, has been continuously supported by investigations for the assessment and improvement of data products. Commissioned studies include the validation of radiometric data such as the $R_{\mathrm{rs}}$ (Cristina et al., 2014; Kajiyama et al., 2014), as well as the analyses of derived product maps (Kajiyama et al., 2014; D'Alimonte et al., 2014; Cristina et al., 2016b). These MERIS validation activities have established an important basis to address Earth observation (EO) capabilities through the Ocean Land Colour Instrument (OLCI) sensor launched on the Sentinel-3 satellite in February 2016. OLCI data products are the main component of the Copernicus European programme to monitor the marine environment, and the retrieval of chlorophyll $a(\mathrm{Chl} a)$ is a core task of the Sentinel-3 space mission. Chl $a$ is needed to estimate the phytoplankton biomass in the ocean and to contribute to a variety of interrelated investigations and applications, including climate data records, environmental legislation, and a number of economic activities such as fisheries and aquaculture. After the removal of the atmospheric contribution to the signal recorded at the top of the atmosphere, Chl $a$ can be estimated from the bottom-of-atmosphere (BOA) $R_{\mathrm{rs}}$ values, using the standard approach with polynomial algorithms based on band ratios of the input radiometric quantities. The corresponding MERIS data product is denoted Algal Pigment Index 1 (API1) (Morel and Antoine, 2011). The use of band ratio is based on the assumption that seawater optical properties are driven by $\mathrm{Chl} a$. A tendency towards overestimation has, however, been documented in optically complex marine conditions (D'Alimonte et al., 2014). This can occur when optically active constituents, such as coloured dissolved or- 
ganic matter (CDOM) and detrital particulate matter, exceed their typical levels. The Chl $a$ retrieval accuracy declines in these optically complex conditions because the band ratio approach attributes variations of the $R_{\mathrm{rs}}$ spectral slope to changes of Chl $a$. In such cases, regionalized bio-optical algorithms are required (Bricaud et al., 2002; Gregg and Casey, 2004). Alternative ocean colour inversion schemes adopted to improve the $\mathrm{Chl} a$ retrieval from space include artificial neural nets (NNs) using $R_{\mathrm{rs}}$ at selected wavelengths as input. In the case of MERIS standard deliverables, this corresponds to the API2 data product (Doerffer and Schiller, 2007).

Although NNs can, in principle, model any relationship between apparent and inherent optical properties, their performance is, in practice, mostly determined by the dataset used for their training. Specific analyses are then needed to compare the standard MERIS API2 results with independent estimates. This main requirement is addressed in the present work by (1) developing and assessing the performance of an independent regional multilayer perceptron (MLP) scheme to retrieve results equivalent to MERIS API2 values; and by (2) comparing MERIS standard and regional API2 product maps.

The region being studied is the Atlantic off the southwestern Iberian Peninsula, where in situ reference data were collected at three stations off the Sagres region at 2, 10, and $18 \mathrm{~km}$ from the coast (henceforth, stations A, B, and C, respectively). The study is conducted based on both matchup analyses and product map intercomparisons, with timely presentation of the results acknowledging not only the planned MERIS data reprocessing but also the need for a benchmark for the analysis of the upcoming OLCI API2 deliverables. An added value of this study is to confirm that qualitative evaluations based on product map comparison can complement matchup data at the early mission stages of OLCI, when the statistical significance of matchup analysis is limited.

\section{Data and methods}

Field campaigns were performed from 2008 to 2012 at the three study sites, with simultaneous collection of water samples and radiometric measurements. MERIS level 2 full resolution (FR, $290 \mathrm{~m} \times 260, \mathrm{~m})$ and reduced resolution (RR, $1.20 \mathrm{~km} \times 1.04 \mathrm{~km}$ ) satellite images were extracted for matchup analysis and product map comparison, respectively, and analysed with the Basic ERS \& ENVISAT (A) ATSR and MERIS Toolbox (BEAM version 4.9). The MEGS 8.1 processor (MERIS third reprocessing) was used to derive level 2 data, in agreement with previously reported extraction procedures (Cristina et al., 2014, 2015). The selection of satellite images was restricted to images without clouds and contamination, as indicated by not having specific product confidence (PCD), sun glint, and ice flags. More details on the image selection criteria and full description of flags are reported in Cristina et al. (2016a). TChl $a$ concentration (monovinyl
Chl $a+$ divinyl Chl $a+$ chlorophyllide $a+$ phaeopigments) was determined by high-performance liquid chromatography (HPLC), according to Wright and Jeffrey (1997), herein referred to as TChl $a_{\mathrm{HPLC}}^{\mathrm{REF}}$. The protocols adopted for TChl $a$ extraction, identification, and quantification procedures are reported in Goela et al. $(2014,2015)$.

\subsection{In situ reference data}

In situ radiometric measurements were acquired with a tethered attenuation coefficient chain sensor (TACCS, Satlantic ${ }^{\circledR}$ ), supporting a hyperspectral surface irradiance sensor $E_{\mathrm{s}}(\lambda)$ and a subsurface radiance sensor $L_{\mathrm{u}}(\lambda)$, as well as a tethered attenuation chain equipped with four irradiance sensors at nominal depths of 2, 4, 8, and $16 \mathrm{~m}$. Normalized water leaving reflectance $\left(\rho_{\mathrm{N}}\right)$ was computed with Eq. (1):

$\rho_{\mathrm{N}}(\lambda)=\pi \frac{L_{\mathrm{w}}(\lambda)}{E_{\mathrm{S}}(\lambda)}$,

where $L_{\mathrm{w}}$ is the water leaving radiance determined by propagating $L_{\mathrm{u}}$ from below to above the sea surface and corrected for self-shading following Gordon and Ding (1992). $\rho_{N}(\lambda)$ corresponds to the remote sensing reflectance $R_{\mathrm{rs}}$ upon scaling with $\pi$.

For the determination of in situ absorption of phytoplankton pigments at $442 \mathrm{~nm}\left(a_{\mathrm{ph}}(442)\right)$, seawater filtrates $(0.5 \mathrm{~L})$ were collected on GF/F filters (pore size $0.7 \mu \mathrm{m}$ ), which were then analysed with the transmittance-reflectance technique of Tassan and Ferrari (2002), using a dual beam spectrophotometer (GBC ${ }^{\circledR}$ CINTRA 40), equipped with an integrating sphere. The phytoplankton absorption was determined as the difference between the total particulate and detrital absorption, which were measured before and after sodium hypochlorite bleaching (Ferrari and Tassan, 1999; Goela et al., 2013), respectively. The API2 in situ equivalent algal pigment index TChl $a_{\mathrm{ABS}}^{\mathrm{REF}}$ was then estimated by converting $a_{\mathrm{ph}}(442)$ into API2, using the same regression coefficients presented in Sect. 2.2.2.

\subsection{Chlorophyll $a$ retrieval algorithms}

\subsubsection{MERIS standard algorithm API2}

This standard product is estimated with two NNs. The first NN computes BOA $R_{\mathrm{rs}}$ values by removing the atmospheric radiometric contribution from input space-borne $R_{\mathrm{rs}}$ values. The second NN utilizes the BOA $R_{\mathrm{rs}}$ to derive the $a_{\mathrm{ph}}(442)$. The final API2 product is then computed as $\mathrm{MER}^{\mathrm{API} 2}=A \times a_{\mathrm{ph}}(442)^{B}$, with power-law regression coefficients $A=21.0$ and $B=1.04$ derived from field measurements in the German Bight and Norwegian waters (Doerffer and Schiller, 2007). 
Table 1. Comparison of the standard (MER $\left.{ }^{\mathrm{API} 2}\right)$, the regional bio-optical algorithms $\mathrm{MLP}\left(R_{\mathrm{rS}}^{\mathrm{MER}}\right)$ and $\mathrm{MLP}\left(R_{\mathrm{rs}}^{\mathrm{SITU}}\right)$, and the TChl $a^{\mathrm{REF}}$.

\begin{tabular}{|c|c|c|c|c|c|c|c|c|c|c|c|c|c|c|c|c|}
\hline & \multicolumn{4}{|c|}{$N$} & \multicolumn{4}{|c|}{$\varepsilon(\%)$} & \multicolumn{4}{|c|}{$\delta(\%)$} & \multicolumn{4}{|c|}{$r^{2}$} \\
\hline & A & B & $\mathrm{C}$ & All & A & B & $\mathrm{C}$ & All & A & B & $\mathrm{C}$ & All & A & B & $\mathrm{C}$ & All \\
\hline MER $^{\mathrm{API} 2}$ vs. $T \mathrm{Chl} a_{\mathrm{ABS}}^{\mathrm{REF}}$ & 18 & 17 & 19 & 54 & 45 & 35 & 38 & 39 & -35 & -32 & -34 & -34 & 0.22 & 0.60 & 0.67 & 0.49 \\
\hline MER $^{\mathrm{API} 2}$ vs. $T \mathrm{Chl} a_{\mathrm{HPLC}}^{\mathrm{REF}}$ & 18 & 17 & 19 & 54 & 48 & 39 & 42 & 43 & -21 & -24 & -26 & -24 & 0.18 & 0.54 & 0.66 & 0.38 \\
\hline $\operatorname{MLP}\left(R_{\mathrm{rs}}^{\mathrm{MER}}\right)$ vs. $T \mathrm{Chl} a_{\mathrm{ABS}}^{\mathrm{REF}}$ & 18 & 17 & 19 & 54 & 23 & 32 & 30 & 29 & 8 & 8 & 16 & 11 & 0.69 & 0.51 & 0.85 & 0.67 \\
\hline $\operatorname{MLP}\left(R_{\mathrm{rs}}^{\mathrm{MER}}\right)$ vs. $T \mathrm{Chl} a_{\mathrm{HPLC}}^{\mathrm{REF}}$ & 18 & 17 & 19 & 54 & 66 & 45 & 49 & 54 & 39 & 16 & 30 & 29 & 0.38 & 0.49 & 0.49 & 0.43 \\
\hline $\operatorname{MLP}\left(R_{\mathrm{rs}}^{\mathrm{SITU}}\right)$ vs. $T \mathrm{Chl} a_{\mathrm{ABS}}^{\mathrm{REF}}$ & 93 & 91 & 113 & 297 & 16 & 17 & 19 & 17 & 3 & -4 & 7 & 2 & 0.88 & 0.91 & 0.91 & 0.91 \\
\hline $\operatorname{MLP}\left(R_{\mathrm{rs}}^{\mathrm{SITU}}\right)$ vs. $T \mathrm{Chl} a_{\mathrm{HPLC}}^{\mathrm{REF}}$ & 93 & 91 & 113 & 297 & 56 & 35 & 39 & 43 & 27 & 7 & 20 & 18 & 0.48 & 0.86 & 0.61 & 0.63 \\
\hline
\end{tabular}

\subsubsection{Regional MLP NN algorithm}

The regional MLP for retrieving the data product equivalent to API2 has been trained with the in situ data collected at the Sagres site (instructions for independent implementation by users are provided at the web link http://ocportugal.org/sites/ default/files/mlpSgrAPI2.pdf). This MLP is here applied to two different sets of input data for assessment of performance and for comparison of results. The first set consists of the in situ $R_{\mathrm{rS}}$ values $\left(R_{\mathrm{rs}}^{\mathrm{STU}}\right)$, and the second set includes standard MERIS BOA $R_{\mathrm{rs}}$ data $\left(R_{\mathrm{rs}}^{\mathrm{MER}}\right)$. Corresponding data products are denoted $\operatorname{MLP}\left(R_{\mathrm{rs}}^{\mathrm{SITU}}\right)$ and $\operatorname{MLP}\left(R_{\mathrm{rs}}^{\mathrm{MER}}\right)$, respectively. In both cases, $R_{\mathrm{rs}}$ at 490,510 , and $560 \mathrm{~nm}$ were selected as input channels, in agreement with the reference study (Cristina et al., 2014).

A novelty detection scheme (D'Alimonte et al., 2014; Bishop, 1994) was used to verify the algorithm applicability range by evaluating the representativeness of the input data in the training dataset (D'Alimonte et al., 2003; Mélin et al., 2011; Sá et al., 2015). The adopted applicability range is based on a novelty index $(\eta)$ presented in published works (D’Alimonte et al., 2013; Sá et al., 2015). A revision is, however, applied for the scope of this work. This updated version considers all dimensions of the principal component analysis (PCA) of selected input data, rather than only the first three components considered in the past (see http://ocportugal.org/sites/default/files/mlpSgrAPI2.pdf for details). This updated definition is more effective for cases where the variability of training and application data tends to occur at different wavelengths (details not presented here). Key features are the following: (1) $\eta$ is bounded between 0 and $\infty$; (2) the more the $R_{\mathrm{rs}}$ spectrum is similar to the in situ MLP training measurements, the lower is its $\eta$; and (3) an $R_{\text {rs }}$ spectrum is considered within the MLP applicability range when $\eta \leq 1$.

\section{Results}

The main tasks of this study are the following: (1) to evaluate the performance of regional MLP algorithm and the $\mathrm{MER}^{\mathrm{API} 2}$ results with respect to the in situ TChl $a_{\mathrm{ABS}}^{\mathrm{REF}}$ ref- erence measurements; (2) to verify the applicability of the regional $\operatorname{MLP}\left(R_{\mathrm{rs}}^{\mathrm{MER}}\right)$ and to compare product maps with MERIS algal pigment indices; and (3) to extend the analysis by also considering TChl $a_{\mathrm{HPLC}}^{\mathrm{REF}}$ for data product assessment. The main results are summarized in Table 1 .

The statistical figures used to evaluate the estimated $(y)$ in relation to the reference in situ TChl $a(x)$ are absolute $(\varepsilon)$ and signed $(\delta)$ percent differences, defined as

$\varepsilon=\frac{1}{N} \sum_{i=1}^{N} \frac{\left|y_{i}-x_{i}\right|}{x_{i}} \times 100 ; \delta=\frac{1}{N} \sum_{i=1}^{N} \frac{y_{i}-x_{i}}{x_{i}} \times 100$,

where $N$ is the total number of samples and $i$ is the sample index. For product map comparison, the absolute $\left(\varepsilon^{*}\right)$ and signed $\left(\delta^{*}\right)$ unbiased differences are instead determined as

$\varepsilon^{*}=\frac{1}{N} \sum_{i=1}^{N} \frac{\left|y_{i}-x_{i}\right|}{y_{i}+x_{i}} \times 200 ; \delta^{*}=\frac{1}{N} \sum_{i=1}^{N} \frac{y_{i}-x_{i}}{y_{i}+x_{i}} \times 200$

where $x_{i}$ and $y_{i}$ are the $\operatorname{MLP}\left(R_{\mathrm{rs}}^{\mathrm{MER}}\right)$ and $\mathrm{MER}^{\mathrm{API} 2}$ values, respectively, taking the mean of the two values as a reference. In addition, the coefficient of determination $\left(r^{2}\right)$ between the evaluated quantities is also reported. The total number of samples used to validate $\mathrm{MER}^{\mathrm{API} 2}$ and $\operatorname{MLP}\left(R_{\mathrm{rs}}^{\mathrm{MER}}\right)$ algorithm results, with respect to the in situ reference measurements, is $N=54$. In contrast, the total number of samples for assessing the performance of the regional MLP algorithm with in situ reference measurements $\operatorname{MLP}\left(R_{\mathrm{rs}}^{\mathrm{SITU}}\right)$ is $N=297$. This larger number of samples is based on the data from four to eight radiometric casts for each in situ TChl $a$ sample at each location.

\subsection{Matchup data analysis}

The top panels of Fig. 1 present the matchup comparisons of $\mathrm{MER}^{\mathrm{API} 2}, \operatorname{MLP}\left(R_{\mathrm{rs}}^{\mathrm{MER}}\right)$, and $\operatorname{MLP}\left(R_{\mathrm{rs}}^{\mathrm{SITU}}\right)$ with respect to the in situ reference TChl $a_{\mathrm{ABS}}^{\mathrm{REF}}$ (Fig. 1a-c, respectively). While MER ${ }^{\mathrm{API} 2}$ underestimates TChl $a(\delta=-34 \%)$ especially at higher concentrations, the regional products slightly overestimate TChl $a: \delta=11 \%$ for $\operatorname{MLP}\left(R_{\mathrm{rs}}^{\mathrm{MER}}\right)$ and $2 \%$ for $\operatorname{MLP}\left(R_{\mathrm{rs}}^{\mathrm{SITU}}\right)$. The best agreement between datasets is ob- 


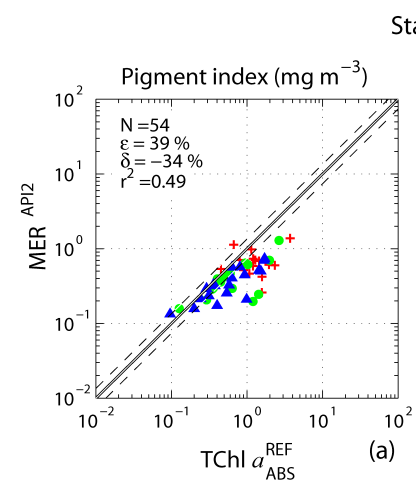

Station A +

Station B -

Station C A
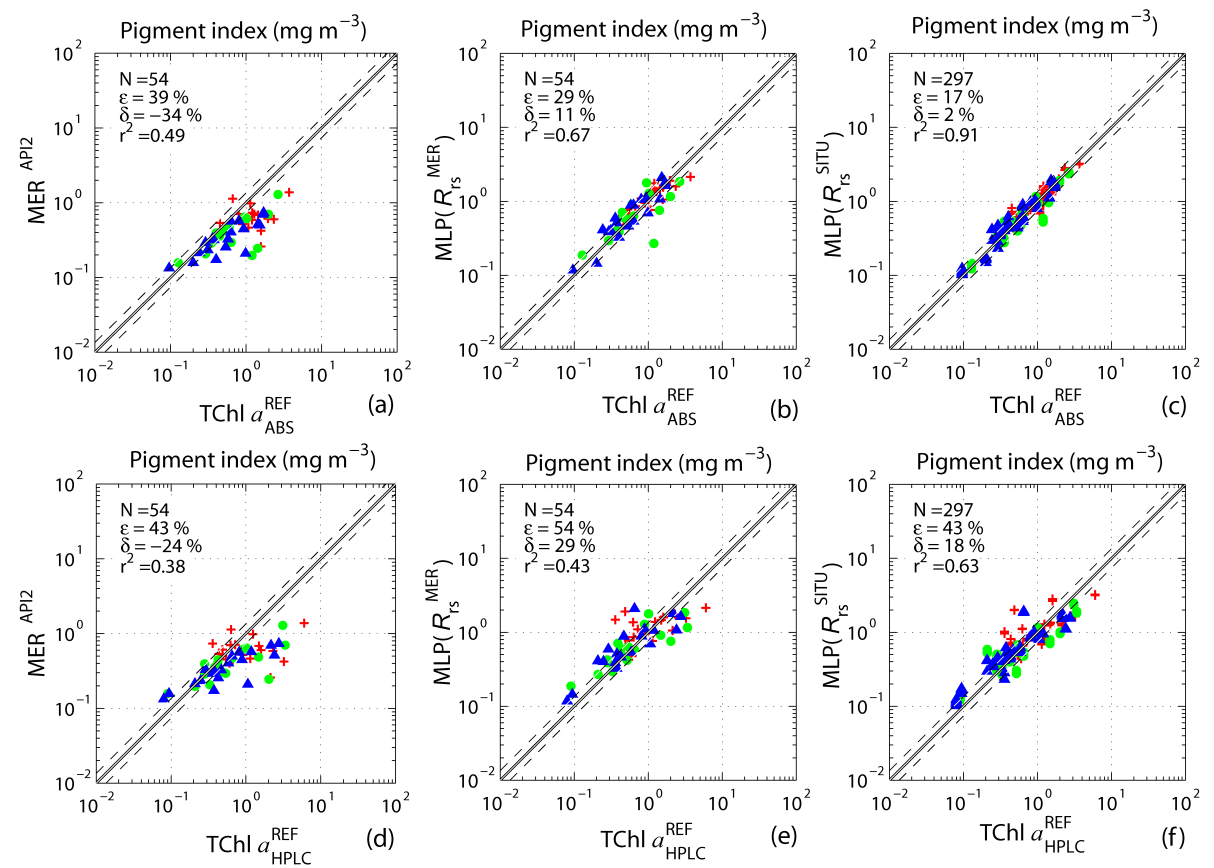

Figure 1. Comparison between MERIS standard Algal Pigment Index 2 and results obtained by applying the multilayer perceptron (MLP) regional scheme for the Sagres region. The top row panels present the matchup comparisons with respect to the in situ reference TChl $a_{\mathrm{ABS}}^{\mathrm{REF}}$, while the lower panels detail the matchup comparisons with TChl $a_{\mathrm{HPLC}}^{\mathrm{REF}}$.

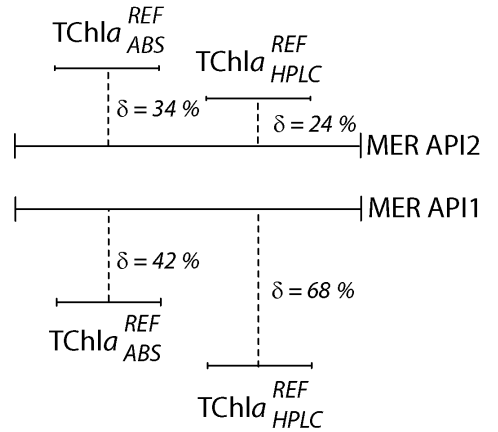

(a)

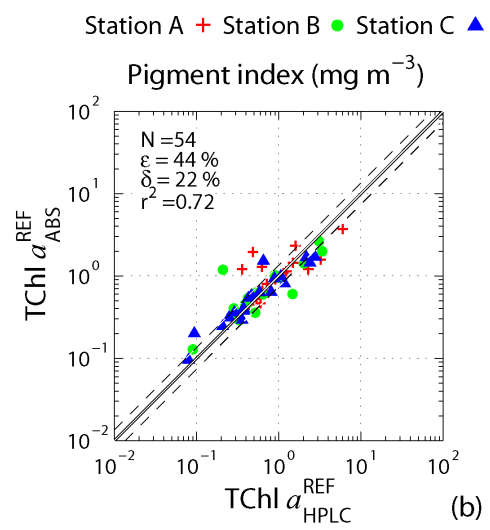

Figure 2. (a) Schematic diagram showing, respectively, underestimation and overestimation of MERIS Algal Pigment Indices 1 and 2 , relative to TChl $a$, estimated through the absorption coefficient at $442 \mathrm{~nm}$ (TChl $a_{\mathrm{ABS}}^{\mathrm{REF}}$ ) and measured by HPLC (TChl $a_{\mathrm{HPLC}}^{\mathrm{REF}}$ ), and (b) scatter plot of the TChl $a_{\mathrm{ABS}}^{\mathrm{REF}}$ vs. TChl $a_{\mathrm{HPLC}}^{\mathrm{REF}}$.

tained with $\mathrm{MLP}\left(R_{\mathrm{rs}}^{\mathrm{SITU}}\right)$, while $\mathrm{MER}^{\mathrm{API} 2}$ shows larger uncertainties. The matchup analysis in Table 1 shows that the underestimation of MER API2 in relation to TChl $a$ is relatively constant $(35,32$, and $34 \%$, at stations A, B and C, respectively) at all stations, but the correlation coefficient improves with distance offshore $(0.22,0.60$, and 0.67 at stations $\mathrm{A}, \mathrm{B}$, and $\mathrm{C}$, respectively).

In general, the matchup analysis with TChl $a_{\mathrm{HPLC}}^{\mathrm{REF}}$ reveals higher uncertainties for $\operatorname{MER}^{\mathrm{API} 2}, \operatorname{MLP}\left(R_{\mathrm{rs}}^{\mathrm{MER}}\right)$, and
$\operatorname{MLP}\left(R_{\mathrm{rs}}^{\mathrm{SITU}}\right)$, as detailed in Fig. 1 (lower panel). Note that also in this case $\operatorname{MLP}\left(R_{\mathrm{rs}}^{\mathrm{SITU}}\right)$ presents the best results, with the highest coefficient of determination and the lowest bias. Similar to what has been documented for TChl $a_{\mathrm{ABS}}^{\mathrm{REF}}$, the bias for TChl $a_{\mathrm{HPLC}}^{\mathrm{REF}}$ displays only small differences between the sampling stations. The coefficient of determination instead increases from station $\mathrm{A}$ to station $\mathrm{C}$. The underestimation of MER ${ }^{\mathrm{API} 2}$ in relation to TChl $a_{\mathrm{HPLC}}^{\mathrm{REF}}$ is also observed, but with a lower bias (Fig. 1d). These observations are schema- 


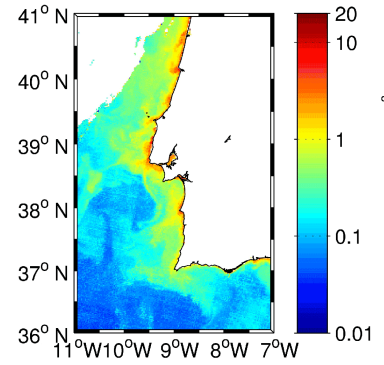

(a)

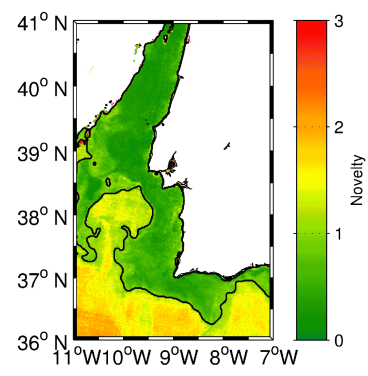

(d)

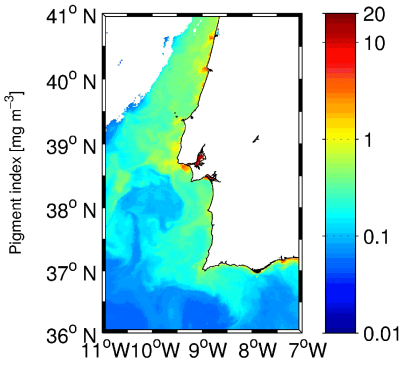

(b)

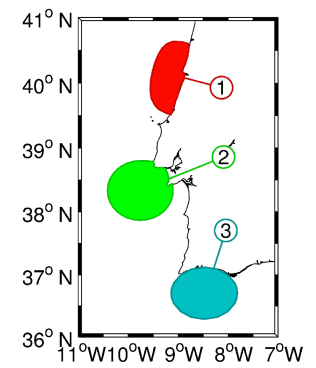

(e)

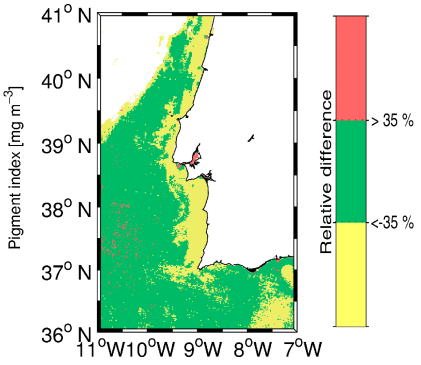

(c)

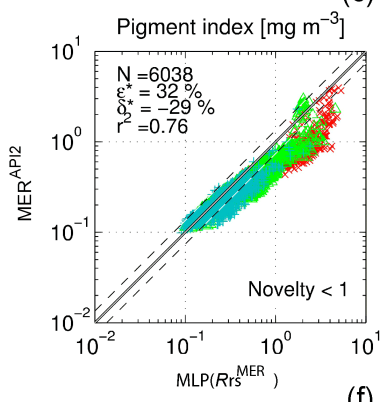

(f)

Figure 3. Comparison between the Sagres regional MLP algorithm map and the MERIS pigment index product map for Algal Pigment Index 2 on 25 August 2010, showing (a) the product map of the regional MLP, (b) standard API2 MERIS product map, (c) difference between $\operatorname{MER}^{\mathrm{API} 2}$ and $\operatorname{MLP}\left(R_{\mathrm{rs}}^{\mathrm{MER}}\right)$, (d) region of applicability of $\operatorname{MLP}\left(R_{\mathrm{rs}}^{\mathrm{MER}}\right)$, (f) results of the application of the regional MLP to the Portuguese coast in the three regions of interest shown in (e). Please see Sect. 3.2 for a more detailed description of the panels (source: MER_RR_2PRAC20100825_103551_000026292092_00223_44365_0000.N1).

tized in Fig. 2, where MER ${ }^{\mathrm{API} 2}$ is considered as the baseline. A complementary comparison with MER ${ }^{\mathrm{API} 1}$ is considered for completeness. Results indicate an overestimation by the API1 algorithm in relation to both estimations of TChl $a$ (details not shown). The tendency of TChl $a_{\mathrm{ABS}}^{\mathrm{REF}}$ to produce higher values than TChl $a_{\mathrm{HPLC}}^{\mathrm{REF}}$ is also confirmed.

\subsection{Comparison of product maps}

The comparison of MERIS API2 standard product with the MLP regional results is presented in Fig. 3. The maps for the regional MLP (Fig. 3a) and the MER ${ }^{\mathrm{API}}$ (Fig. 3b) are shown in the top panel, together with the difference between MER ${ }^{\mathrm{API} 2}$ and $\mathrm{MLP}\left(R_{\mathrm{rs}}^{\mathrm{MER}}\right)$ shown in Fig. 3c. Overestimations of more than $35 \%$ in relation to the regional MLP are coloured in pink, and underestimations below $35 \%$ are coloured in yellow, while differences between -35 and $35 \%$ are in green. The $\operatorname{MLP}\left(R_{\mathrm{rs}}^{\mathrm{MER}}\right)$ region of applicability is shown in Fig. 3d, with black contours indicating the threshold $\eta=1$. Results indicate an underestimation by MER ${ }^{\mathrm{API} 2}$ of more than $35 \%$ in a significant part of the applicability range, especially near the coast.

The results from the application of Sagres regional MLP to the Atlantic off the Portuguese coast is presented in Fig. 3e and $\mathrm{f}$. Besides the Sagres area (no. 3, in blue), two other regions of interest (ROIs) have been chosen for comparison of product maps: Figueira da Foz (no. 1, in red) and the Lisbon region (no. 2, in green; Fig. 3e). Note that ROIs no. 1
Table 2. Comparison between the regional $\operatorname{MLP}\left(R_{\mathrm{rS}}^{\mathrm{MER}}\right)$ and the standard MER API2 (the locations of ROIs are presented in Fig. 3e).

\begin{tabular}{lrrrrr}
\hline ROI & $N_{\text {tot }}$ & $N_{\text {val }}$ & $\varepsilon^{*}(\%)$ & $\delta^{*}(\%)$ & $r^{2}$ \\
\hline No. 1 & 2122 & 2075 & 43 & -43 & 0.70 \\
No. 2 & 3383 & 1739 & 32 & -30 & 0.71 \\
No. 3 & 2946 & 2224 & 20 & -15 & 0.76 \\
\hline Total & 8451 & 6038 & 32 & -29 & 0.76 \\
\hline
\end{tabular}

and no. 2 have been selected for their contrasting features: the first is influenced by the Mondego River plume and the second by the Tagus estuary. The comparison between the MER $^{\mathrm{API} 2}$ and regional MLP products is presented as a scatter plot (Fig. 3f), following the same colour coding of the three ROIs. The underestimation tendency of MER ${ }^{\mathrm{API} 2}$ in relation to in situ TChl $a$ is confirmed through this analysis. The results also indicate more pronounced differences in Mondego and Tagus ROIs, where values of TChl $a$ are higher.

The statistical figures of the product map comparison between MER ${ }^{\text {API2 }}$ and regional MLP are summarized in Table 2. The applicability of the Sagres MLP is verified with the novelty detection scheme. The number of total and valid (i.e. $\eta<1)$ data points are denoted as $N_{\text {tot }}$ and $N_{\text {val }}$, respectively. The Sagres ROI presents the highest number of valid 
data points, while the Tagus region has the highest percentage of novel data points.

\section{Discussion}

This study analysed the standard MERIS API2 product by considering the TChl $a$ retrieval in the coastal waters of Portugal. Data product comparisons have been performed by developing and applying a regional MLP trained with Sagres in situ data and accounting for its applicability range. The work highlighted a tendency of MER ${ }^{\mathrm{API} 2}$ to underestimate $\mathrm{TChl} a$, not only when the reference values were derived through $a_{\mathrm{ph}}(442)$, but also when determined by HPLC. This result is consistent with other studies addressing low-productivity waters (Tilstone et al., 2012). This underestimation tendency is more pronounced at higher concentrations but not observed in the results of the regional MLP. Possible explanations can be uncertainties in BOA $R_{\mathrm{rs}}$ values, as well as in specific properties of the NN inversion scheme used to compute the standard API2 values. It is noted that the MERIS NN scheme for API2 retrieval is scoped for global applications in both Case 1 and optically complex waters. This general applicability might limit the algorithm performance in the presence of specific bio-optical relationships at the regional scale. An example could be the upwelling along the coast of Portugal (Loureiro et al., 2005; Goela et al., 2015).

As a contribution to the forthcoming OLCI mission, the present work also provides indications to enhance standard OLCI API2 results by including additional training samples in the synthetic dataset used for the development of the MERIS NN scheme. The overestimation of TChl $a_{\mathrm{ABS}}^{\mathrm{REF}}$ in relation to TChl $a_{\mathrm{HPLC}}^{\mathrm{REF}}$ has been identified in this study as one of the reasons for the systematic difference observed in the comparison of $\mathrm{MER}^{\mathrm{API} 2}$ with both in situ referred targets (Fig. 2b).

The regional MLP using in situ $R_{\mathrm{rs}}$ as input produced highly accurate results (bias of $2 \%$ ), when relating $R_{\mathrm{rs}}^{\mathrm{SITU}}$ to reference measurements of TChl $a_{\mathrm{ABS}}^{\mathrm{REF}}$. When MERIS $R_{\mathrm{rs}}$ is used, the bias is slightly higher, probably due to the uncertainties of the atmospheric correction (Cristina et al., 2014). It is also reported that a cross-validation analysis performed by splitting the in situ data into different subsets to develop and assess the regional MLP documented an increase from 2 to $9 \%$ of the bias (details not presented). As observed for the standard NN inversion schemes, the performance of the regional MLP could be enhanced through a better representation of the optical properties of the study region: the collection of additional field measurements is hence recommended. Another aspect that has been considered is the reduction in bias when the training dataset was TChl $a_{\mathrm{ABS}}^{\mathrm{REF}}$ estimated with $a_{\mathrm{ph}}$ at $440 \mathrm{~nm}$ (7\% of bias). This indicates that the specific selection of the wavelength of the maximum phytoplankton absorption could allow for a better TChl $a$ parameterization and hence also lead to a more accurate regional MLP.
The strong relationship between $R_{\mathrm{rs}}$ and the phytoplankton coefficient of absorbance at $442 \mathrm{~nm}$ suggests the presence of case 1 waters. The better agreement with TChl $a_{\mathrm{ABS}}^{\mathrm{REF}}$ rather than with TChl $a_{\mathrm{HPLC}}^{\mathrm{REF}}$ can be explained by considering that the training of the neural net was performed with TChl $a_{\mathrm{ABS}}^{\mathrm{REF}}$. An additional explanation could be that TChl $a_{\mathrm{ABS}}^{\mathrm{REF}}$ was determined using $a_{\mathrm{ph}}(442)$, which is likely better related to $R_{\mathrm{rs}}$ than TChl $a_{\mathrm{HPLC}}^{\mathrm{REF}}$ (both $a_{\mathrm{ph}}(442)$ and $R_{\mathrm{rs}}$ directly represent optical properties). A caveat would, however, apply to this argument: TChl $a_{\mathrm{HPLC}}^{\mathrm{REF}}$ is a direct measurement of the TChl $a$ concentration, whereas TChl $a_{\mathrm{ABS}}^{\mathrm{REF}}$ is an indirect measurement which has errors associated with the laboratory determination of $a_{\mathrm{ph}}(442)$.

It is also noted that the regional relationship between $a_{\mathrm{ph}}$ at $442 \mathrm{~nm}$ and TChl $a$ retrieved by HPLC is close to that used in $\operatorname{MER}^{\text {API2 }}\left(\right.$ TChl $a_{\text {MERIS }}=21 a_{\mathrm{ph}}(442)^{1.04}$, TChl $a_{\text {SAGRES }}=$ $\left.27 a_{\mathrm{ph}}(442)^{1.13}\right)$. However, the local relationship between TChl $a$ and $a_{\mathrm{ph}}(442)$ corresponds to a coefficient of determination $r^{2}=0.8$. Hence, about $20 \%$ of variability of TChl $a$ is not related to $a_{\mathrm{ph}}(442)$.

The ROI's data analysis indicates lower MERIS API2 values with respect to equivalent results derived with the regional MLP, especially when the TChl $a$ concentration increases. This finding is in good agreement with the matchup results, thereby highlighting the benefit of independent comparison of product maps to qualitatively evaluate data products at an early stage of ocean colour space missions (e.g. OLCI).

\section{Conclusions}

The scope of this technical note was to analyse the MERIS standard API2 product in the southwestern coast of Portugal. A regional MLP algorithm to retrieve TChl $a$, estimated through a phytoplankton absorption coefficient, was implemented and applied for this purpose. This regional algorithm produced good agreement with in situ data, hence indicating a high accuracy of regional MLP products. The applicability of the regional MLP in the study area was verified by a novelty detection scheme. With this information, the study reports an underestimation tendency of $\mathrm{MER}^{\mathrm{API}}$, which is consistent with other European basins within low ranges of this constituent. The results of the regional MLP were closer to the in situ reference for API2 - TChl $a$ estimated with $a_{\mathrm{ph}}(442)$ - than to TChl $a$ determined by HPLC. This work also indicates that the use of a regional relationship between phytoplankton absorption and pigment concentration is expected to improve the accuracy of global ocean colour remote sensing products.

This study has highlighted the usefulness of maintaining in situ measurement programmes for validation purposes of ongoing ocean colour missions. Moreover, it has also demonstrated the importance of developing regional algorithms that not only complement standard approaches but that can also 
be applied for the qualitative data assessments of new ocean colour missions in the early stages of product map delivery (e.g. Sentinel-3).

\section{Data availability}

The majority of the in situ data used in this work can be accessed through the ESA MERIS MAtchup In-situ Database (http://mermaid.acri.fr/home/home.php), and the MERIS satellite data can be accessed through the optical data processor of ESA (http://www.odesa-info.eu/process_basic/ basic.php). 


\section{Appendix A: List of abbreviations}

\begin{tabular}{|c|c|}
\hline API1 & Algal Pigment Index 1 \\
\hline API2 & Algal Pigment Index 2 \\
\hline BEAM & Basic ERS \& ENVISAT (A) ATSR and MERIS Toolbox \\
\hline BOA & Bottom-of-atmosphere \\
\hline $\mathrm{CDOM}$ & Coloured dissolved organic matter \\
\hline Chl $a$ & Chlorophyll $a$ \\
\hline EO & Earth observation \\
\hline$E_{\mathrm{S}}(\lambda)$ & Surface downwelling incident irradiance \\
\hline HPLC & High-performance liquid chromatography \\
\hline$L_{\mathrm{u}}(\lambda)$ & Subsurface upwelling radiance \\
\hline$L_{\mathrm{w}}(\lambda)$ & Water leaving radiance \\
\hline $\mathrm{MER}^{\mathrm{API} 2}$ & MERIS Algal Pigment Index 2 standard product \\
\hline MERIS & MEdium Resolution Image Spectrometer \\
\hline MLP & Multilayer perceptron \\
\hline $\operatorname{MLP}\left(R_{\mathrm{rs}}^{\mathrm{MER}}\right)$ & $\begin{array}{l}\text { Regional TChl } a \text { products computed using inversion schemes } \\
\text { based on the MLP NN using standard MERIS BOA } R_{\mathrm{rs}}\end{array}$ \\
\hline $\operatorname{MLP}\left(R_{\mathrm{rs}}^{\mathrm{SITU}}\right)$ & $\begin{array}{l}\text { Regional TChl } a \text { products computed using inversion schemes } \\
\text { based on the MLP NN using in situ } R_{\mathrm{rs}}\end{array}$ \\
\hline NNs & Neural nets \\
\hline$N_{\text {tot }}$ & Number of total data points \\
\hline$N_{\text {val }}$ & Number of valid data points \\
\hline OLCI & Ocean Land Colour Instrument \\
\hline PCA & Principal component analysis \\
\hline$r^{2}$ & Coefficient of determination \\
\hline ROIs & Regions of interest \\
\hline$R_{\mathrm{rs}}$ & Remote sensing reflectances \\
\hline$R_{\mathrm{rs}}^{\mathrm{MER}}$ & Standard MERIS BOA $R_{\mathrm{rs}}$ \\
\hline$R_{\mathrm{rS}}^{\mathrm{SSTU}}$ & In situ $R_{\mathrm{rs}}$ \\
\hline TChl $a$ & Total chlorophyll $a$ \\
\hline TChl $a_{\mathrm{ABS}}^{\mathrm{REF}}$ & API 2 in situ equivalent algal pigment index \\
\hline TChl $a_{\mathrm{HPLC}}^{\mathrm{AEE}}$ & $\begin{array}{l}\text { TChl } a \text { concentration (monovinyl Chl } a+\text { divinyl Chl } a \\
+ \text { chlorophyllide } a+\text { phaeopigments) determined by HPLC }\end{array}$ \\
\hline$\delta$ & Signed percent differences \\
\hline$\delta^{*}$ & Signed unbiased percent differences \\
\hline$\varepsilon$ & Absolute percent differences \\
\hline$\varepsilon^{*}$ & Absolute unbiased percent differences \\
\hline$\eta$ & Novelty index \\
\hline$\rho_{\mathrm{N}}$ & Normalized water leaving reflectance \\
\hline
\end{tabular}


Acknowledgements. The authors thank Davide D'Alimonte for his contribution to the MLP NN algorithm development and training, and for wise advice both on the methodology design and in the interpretation of the results. This work was supported in part by the European Space Agency (ESA) for the "Technical Assistance for the Validation of MERIS Marine Products at Portuguese oceanic and coastal sites" (contract no. 21464/08/I-O) and "MERIS validation and algorithm 4th reprocessing" (contract no. ARG/003-025/14067Sagremarisco and ARG/003-0251406/CIMA). Priscila Costa Goela and Sónia Cristina were funded by $\mathrm{PhD}$ grants from the Portuguese FCT (SFRH/BD/78356/2011 and SFRH/BD/78354/2011, respectively); Alice Newton was funded by EU FP7 project DEVOTES (grant no. 308392); John Icely is funded by EU FP7 AQUA-USER (grant no. 607325) and Horizon 2020 AquaSpace (grant no. 633476).

Edited by: E. J. M. Delhez

Reviewed by: V. Suslin and one anonymous referee

\section{References}

Bishop, C. M.: Novelty detection and neural network validation, IEE P-Vis Image Sign., 141, 217-222, doi:10.1049/ipvis:19941330, 1994.

Bricaud, A., Bosc, E., and Antoine, D.: Algal biomass and sea surface temperature in the Mediterranean basin, Intercomparison of data from various satellite sensors, and implications for primary production estimates, Remote Sens. Environ., 81, 163-178, 2002.

Cristina, S., Moore, G., Goela, P. C., Icely, J., and Newton, A.: In situ validation of MERIS marine reflectance off the southwest Iberian Peninsula: assessment of vicarious adjustment and corrections for near-land adjacency, Int. J. Remote Sens., 35, 23472377, doi:10.1080/01431161.2014.894657, 2014.

Cristina, S., Icely, J., Goela, P., DelValls, T., and Newton, A.: Using remote sensing as a support to the implementation of the European Marine Strategy Framework Directive in SW Portugal, Cont. Shelf Res., 108, 169-177, doi:10.1016/j.csr.2015.03.011, 2015.

Cristina, S., Cordeiro, C., Lavender, S., Goela, P. G., Icely, J., Moore, G., and Newton, A.: Seasonal-Trend decomposition time series based on Loess applied to MERIS products from the SW Iberian Peninsula: Sagres, Remote Sens., 8, 16 pp., doi:10.3390/rs8060449, 2016a.

Cristina, S., D’Alimonte, D., Goela, P. G., Kajiyama, T., Icely, J., Moore, G., Fragoso, B. D. D., and Newton, A.: Standard and regional bio-optical algorithms for chlorophyll a estimates in the Atlantic off the southwestern Iberian Peninsula, IEEE Geosci. Remote S., 13, 757-761, doi:10.1109/LGRS.2016.2529182, $2016 b$

D’Alimonte, D., Mélin, F., Zibordi, G., and Berthon, J.-F.: Use of the novelty detection technique to identify the range of applicability of empirical ocean colour algorithms, IEEE T. Geosci. Remote, 41, 2833-2843, doi:10.1109/TGRS.2003.818020, 2003.

D'Alimonte, D., Zibordi, G., Kajiyama, T., and Berthon, J.-F.: Comparison between MERIS and regional high-level products in European seas, Remote Sens. Environ., 140, 378-395, doi:10.1016/j.rse.2013.07.029, 2014.
Doerffer, R. and Schiller, H.: The MERIS Case 2 water algorithm, Int. J. Remote Sens., 28, 517-535, doi:10.1080/01431160600821127, 2007.

Ferrari, G. and Tassan, S.: A method using chemical oxidation to remove light absorption by phytoplankton pigments, J. Phycol., 35, 1090-1098, doi:10.1046/j.1529-8817.1999.3551090.x, 1999.

Goela, P., Danchenko, S., Icely, J., Lubian, L., Cristina, S., and Newton, A.: Using CHEMTAX to evaluate seasonal and interannual dynamics of the phytoplankton community off the Southwest coast of Portugal, Estuar., Coast. Shelf S., 151, 112-123, doi:10.1016/j.ecss.2014.10.001, 2014.

Goela, P. C., Icely, J., Cristina, S., Newton, A., Moore, G., and Cordeiro, C.: Specific absorption coefficient of phytoplankton off the southwest coast of the Iberian Peninsula: A contribution to algorithm development for ocean colour remote sensing, Cont. Shelf Res., 52, 119-132, doi:10.1016/j.csr.2012.11.009, 2013.

Goela, P. C., Icely, J., Cristina, S., Danchenko, S., DelValls, T. A., and Newton, A.: Using bio-optical parameters as a tool for detecting changes in the phytoplankton community (SW Portugal), Estuar. Coast. Shelf S., 167, 125-137, doi:10.1016/j.ecss.2015.07.037, 2015.

Gordon, H. R. and Ding, K.: Self-shading of in-water optical instruments, Limnol. Oceanogr., 37, 491-500, doi:10.4319/lo.1992.37.3.0491, 1992.

Gregg, W. W. and Casey, H. W.: Global and regional evaluation of the SeaWiFS chlorophyll data set, Remote Sens. Environ., 93, 463-479, doi:10.1016/j.rse.2003.12.012, 2004.

Kajiyama, T., D'Alimonte, D., and Zibordi, G.: Match-up analysis of MERIS radiometric data in the Northern Adriatic Sea, IEEE Geosci. Remote Sens. Lett., 11, 19-23, doi:10.1109/LGRS.2013.2244844, 2014.

Loureiro, S., Newton, A., and Icely, J.: Microplankton composition, production and upwelling dynamics in Sagres (SW Portugal) during the summer of 2001, Sci. Mar., 69, 323-341, doi:10.3989/scimar.2005.69n3323, 2005.

Mélin, F., Vantrepotte, V., Clerici, M., D’Alimonte, D., Zibordi, G., Berthon, J. F., and Canuti, E.: Multi-sensor satellite time series of optical properties and chlorophyll- $a$ concentration in the Adriatic Sea, Prog. Oceanogr., 91, 229-244, doi:10.1016/j.pocean.2010.12.001, 2011.

Morel, A. and Antoine, D.: Pigment index retrieval in case 1 waters, ATBD 2.9, ESA Doc. No. PO-TN-MEL-GS-0005 (version 4.3), 2011.

Sá, C., D’Alimonte, D., Brito, A., Kajiyama, T., Mendes, C., Vitorino, J., Oliveira, P., Silva, J., and Brotas, V.: Validation of standard and alternative satellite ocean-color chlorophyll products off Western Iberia, Remote Sens. Environ., 168, 403-419, doi:10.1016/j.rse.2015.07.018, 2015.

Tassan S. and Ferrari, G.: A sensitivity analysis of the "Transmittance-Reflectance" method for measuring light absorption by aquatic particles, J. Plankton Res., 24, 757-774, doi:10.1093/plankt/24.8.757, 2002.

Tilstone, G. H., Peters, S. W., Van Der Woerd, H. J., Eleveld, M. A., Ruddick, K., Schönfeld, W., Krasemann, H., MartinezVicente, V., Blondeau-Patissier, D., Röttgers, R., Sørensen, K., Jørgensen, P. V., and Shutler, J. D.: Variability in specificabsorption properties and their use in a semi-analytical ocean colour algorithm for MERIS in North Sea and Western English 
Channel Coastal Waters, Remote Sens. Environ., 118, 320-338, doi:10.1016/j.rse.2011.11.019, 2012.

Wright, S. and Jeffrey, S.: High-resolution HPLC system for chlorophylls and carotenoids of marine phytoplankton, in: Phytoplankton pigments in oceanography, UNESCO Publ., 327-341, 1997. 